\section{XAFS imaging of Tsukuba gabbroic rocks: area analysis of chemical composition and local structure}

\author{
Mari Mizusawa and Kenji Sakurai ${ }^{*}$
}

National Institute for Materials Science, 1-2-1 Sengen, Tsukuba, Ibaraki 305-0047, Japan. E-mail: sakurai@yuhgiri.nims.go.jp

Gabbroic rocks were collected at Mount Tsukuba in Japan, and their XAFS images were studied using a projection-type X-ray fluorescence (XRF) microscope, which is a powerful new tool recently developed for extremely rapid imaging. The instrument employs a grazing-incidence arrangement in order that primary X-rays illuminate the whole sample surface, as well as parallel-beam optics and an extremely close geometry in order to detect XRF by a highperformance X-ray CCD system with $1024 \times 1024$ pixels. The XRF image indicated that black amphibole and white feldspar, both of which are typical mineral textures of the rock, contain iron. The origin has been suggested to be several small yellowish-brown minerals contained there. The XAFS imaging has been carried out by repeating the exposure of XRF images during the energy scan of the primary X-rays. It has been found that the structure is qualitatively close to that of olivine, and the main differences found in both areas can be explained as a difference in iron and magnesium concentration, i.e. the mixed ratio of forsterite $\left(\mathrm{Mg}_{2} \mathrm{SiO}_{4}\right)$ and fayalite $\left(\mathrm{Fe}_{2} \mathrm{SiO}_{4}\right)$. The feasibility of the present XAFS imaging method has been demonstrated for realistic inhomogeneous minerals.

Keywords: X-ray fluorescence; non-scanning imaging; projection microscope; iron; olivine; amphibole; feldspar.

\section{Introduction}

Mount Tsukuba is a solitary mountain sitting on the northeastern edge of the Kanto plain in Japan, at a height of $876 \mathrm{~m}$ from sea level. Gabbroic rocks, which were formed by erosion 7500 million years ago, are found only near the summit, while other well known rocks, such as granite, are most common at the bottom of the mountain (Miyazaki et al., 1996). Tsukuba gabbroic rocks, which are a group of olivine gabbro, hornblende gabbro, cortlandite, spessartite, anorthosite and other rocks, exhibit excellent stability in their mechanical and chemical nature, and contribute to maintain the unique shape of the mountain summit. It has been reported that the rocks contain colored minerals, which are identified as a group of amphiboles (in most cases hornblende), pyroxene (monoclinic pyroxene and orthorhombic pyroxene), biotite, actinolite and olivine. The rocks also contain white minerals, which are mainly a group of feldspar (in most cases plagioclase). In order to understand the geological history of Mount Tsukuba, it is significant to clarify the chemical composition and also the crystallographic structure of minerals contained in these gabbroic rocks. In addition, from a viewpoint of materials science, it is interesting that such naturally formed rocks have excellent mechanical properties, which concerns the chemical composition and structure.

Obviously each mineral consists of a variety of metallic and nonmetallic elements. In particular, iron is extremely important, since the total amount existing on the earth is quite large (Clarke number 4.70), and also for most cases iron is the heaviest of the major elements contained in gabbroic rocks. The atomic level structure around iron contained in each mineral is one of the most interesting subjects. Although some previous studies required the decomposition and extraction of each grain from rock samples (Welch \& Knight, 1999; Yang \& Hirschmann, 1995), non-destructive analysis is highly desirable in order to ensure evaluation by several different methods. Although, in general, X-ray absorption fine structure (XAFS) is a strong tool for obtaining such information, a potential problem is that the technique requires a uniform sample. The rock sample is inhomogeneous in most cases, and it is necessary to obtain XAFS spectra for each area.

Synchrotron X-ray fluorescence (XRF) microscopic analysis can give a series of XAFS spectra for different positions in the fluorescence mode. In addition to a conventional scanning XRF microscope, a non-scanning method using a CCD camera has recently become available (Sakurai, 1999; Sakurai \& Eba, 2003). The technique gives an XRF image of $1024 \times 1024$ pixels in a very short measuring time, typically of the order of $0.1-10 \mathrm{~s}$. This roughly means that $1 \times 10^{6}$ XAFS spectra can be obtained simultaneously just by repeating the exposure during the scan of the monochromator, in a fairly short measuring time, typically a few minutes to $1 \mathrm{~h}$ in total (Sakurai \& Mizusawa, 2004). The advantage of this method is its efficiency, since a conventional scanning XRF microscope requires rather a long measuring time, especially when a large number of pixels are required. This novel XAFS imaging method is a powerful tool for investigating spatially inhomogeneous systems, i.e. inside the grains, along the boundaries etc.

In the present paper the first application of this technique to a rock sample is described. Fe $K$-edge XAFS images of Tsukuba gabbroic rocks will be presented, and the atomic level structure will be discussed, particularly from the viewpoint of the identification of different colored grains.

\section{Experimental}

The samples studied in the present research are gabbroic rocks collected near the summit of Mount Tsukuba in Japan. From their appearance they seem to be a mixture or an intermediate phase of hornblende gabbro and cortlandite. The samples were cut and sliced for measurement, a typical size being $20 \mathrm{~mm} \times 30 \mathrm{~mm} \times 10 \mathrm{~mm}$. The surface was polished with fine alumina powder of radius $50 \mu \mathrm{m}$.

Synchrotron experiments were performed using a flat Si (111) double-crystal monochromator at the multipole-wiggler beamline, BL-16A1, at the Photon Factory, KEK, Japan. The XAFS images were observed by a non-scanning XRF microscope, which combines grazing-incidence geometry $\left(0-2^{\circ}\right)$ using a rather wide beam $[0.6 \mathrm{~mm}$ $(\mathrm{V}) \times 13.3 \mathrm{~mm}(\mathrm{H})]$, and parallel optics $(\sim 6 \mathrm{mrad})$ for detecting X-rays using a CCD camera (Marconi CCD47-10 Class 1, $1024 \times$ 1024 pixels, pixel size $13 \mu \mathrm{m} \times 13 \mu \mathrm{m}$, Peltier cooling $243 \mathrm{~K}$ ). The spatial resolution was confirmed as $15-20 \mu \mathrm{m}$ by X-ray images of standard patterns. Further instrumental details have been described elsewhere (Sakurai, 1999; Sakurai \& Eba, 2003). XRF images were taken during the scan of the incident X-ray energy across the $\mathrm{Fe}$ $K$-absorption edge $(7111 \mathrm{eV})$. The exposure time was $10 \mathrm{~s}$ for each image. The typical number of images was $\sim 250$.

In addition, an optical microscope (Carton), a metallurgical microscope with polarizer units (BX-60, Olympus), an X-ray powder diffractometer (RINT2500, Rigaku) and an electron-probe microanalyzer (JXR8900R, Jeol) were employed for characterization of the samples. 
Table 1

Chemical composition of Tsukuba gabbroic rock obtained using the electron-probe microanalyzer.

Areas $A$ and $B$ are shown in Fig. 1. $A^{\prime}$ are small yellowish-brown grains contained in black area $A$. In area $B$, colored grains are also found, but significant differences with area $B$ were not proved by an electron-probe microanalyzer.

\begin{tabular}{|c|c|c|c|c|c|c|c|c|}
\hline & Area & $\mathrm{Fe}$ & $\mathrm{Si}$ & Mn & $\mathrm{Ca}$ & $\mathrm{Al}$ & $\mathrm{Mg}$ & $\mathrm{O}$ \\
\hline Concentration [at \% (wt \%)] & $\begin{array}{l}A \\
\text { (black) } \\
A^{\prime} \\
\text { (yellowish-brown) } \\
B \\
\text { (white) }\end{array}$ & $\begin{array}{l}4.51 \\
(11.81) \\
6.12 \\
(15.52) \\
0.03 \\
(0.08)\end{array}$ & $\begin{array}{l}9.94 \\
(13.19) \\
21.03 \\
(26.82) \\
16.98 \\
(21.92)\end{array}$ & $\begin{array}{l}0.02 \\
(0.05) \\
0.15 \\
(0.37) \\
0.00 \\
(0.01)\end{array}$ & $\begin{array}{l}0.01 \\
(0.01) \\
0.36 \\
(0.65) \\
7.23 \\
(13.31)\end{array}$ & $\begin{array}{l}9.30 \\
(11.75) \\
0.29 \\
(0.35) \\
14.63 \\
(18.14)\end{array}$ & $\begin{array}{l}11.70 \\
(13.33) \\
10.92 \\
(12.05) \\
0.00 \\
(0.00)\end{array}$ & $\begin{array}{l}64.52 \\
(43.37) \\
61.14 \\
(44.41) \\
61.13 \\
(44.93)\end{array}$ \\
\hline
\end{tabular}

Table 2

Chemical composition of Tsukuba gabbroic rock obtained by ICP.

Definitions of areas $A, A^{\prime}$ and $B$ are common as written in Table 1.

\begin{tabular}{|c|c|c|c|c|c|c|c|c|c|c|}
\hline & Area & $\mathrm{Fe}$ & $\mathrm{Si}$ & $\mathrm{Mn}$ & $\mathrm{Ca}$ & $\mathrm{Al}$ & $\mathrm{Mg}$ & $\mathrm{Na}$ & $\mathrm{K}$ & $\mathrm{O}$ \\
\hline Concentration [wt $\%]$ & $\begin{array}{l}A+A^{\prime} \text { (black, yellowish-brown) } \\
B \text { (white) }\end{array}$ & $\begin{array}{c}12.3 \\
0.68\end{array}$ & $\begin{array}{l}21.7 \\
20.0\end{array}$ & $\begin{array}{l}0.23 \\
0.012\end{array}$ & $\begin{array}{c}3.12 \\
10.4\end{array}$ & $\begin{array}{c}4.87 \\
17.7\end{array}$ & $\begin{array}{c}10.6 \\
0.47\end{array}$ & $\begin{array}{l}0.21 \\
0.93\end{array}$ & $\begin{array}{r}<0.1 \\
0.2\end{array}$ & $\begin{array}{l}\text { Balance } \\
\text { Balance }\end{array}$ \\
\hline
\end{tabular}

\section{Results and discussions}

An optical-microscope photograph of the Tsukuba gabbroic rock surface is shown in Fig. 1(a). The minerals show an inhomogeneous distribution and consist of roughly two typical independent parts, black $(A)$ and white $(B)$ areas. Furthermore, there are some small yellowish-brown grains $(0.1-0.4 \mathrm{~mm}$ in diameter) in both areas. In area $A$, the grains are quite easily visible ( $A^{\prime}$ grains). In area $B$, small black grains are also found. As shown in Figs. $1(b)$ and $1(c)$, observation by a polarization microscope (reflection mode) indicates that three and two different mineral textures are found in areas $A$ and $B$, respectively. In area $A$, one can see black uniform, grey stripepatterned and yellowish-brown particle-like textures, which are roughly identified as amphiboles, actinolite and olivine, respectively. The particle shows the contrast which does not depend on the polarization. The structure inside the particle is not uniform; yellowish-brown parts are surrounded by a whitish shell. On the other hand, the white part $(B)$, which is attributed to feldspar, is quite uniform, although this includes small particle-like texture as well. Yellowish-brown particles are not so clear in comparison with area $A$.

The chemical composition of the two areas $A$ and $B$ was analyzed by an electron-probe microanalyzer and inductively coupled plasma spectroscopy (ICP). The results are listed in Tables 1 and 2. In the ICP analysis it was not possible to separate the yellowish-brown $A^{\prime}$ grains from other black grains in $A$, and therefore the analysis was

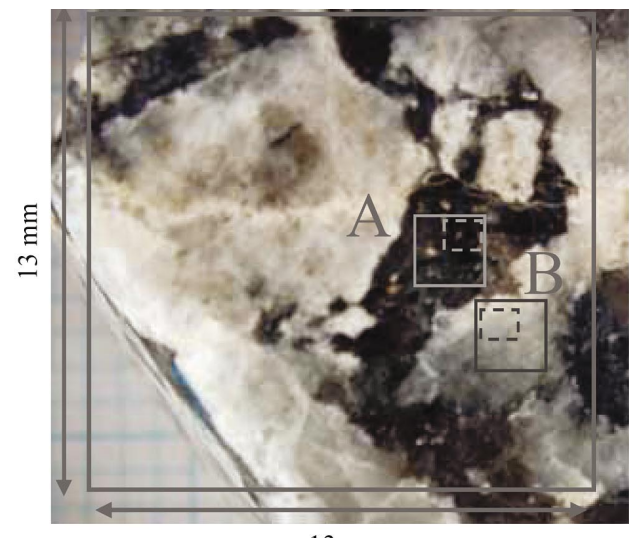

$13 \mathrm{~mm}$

(a) Observed area
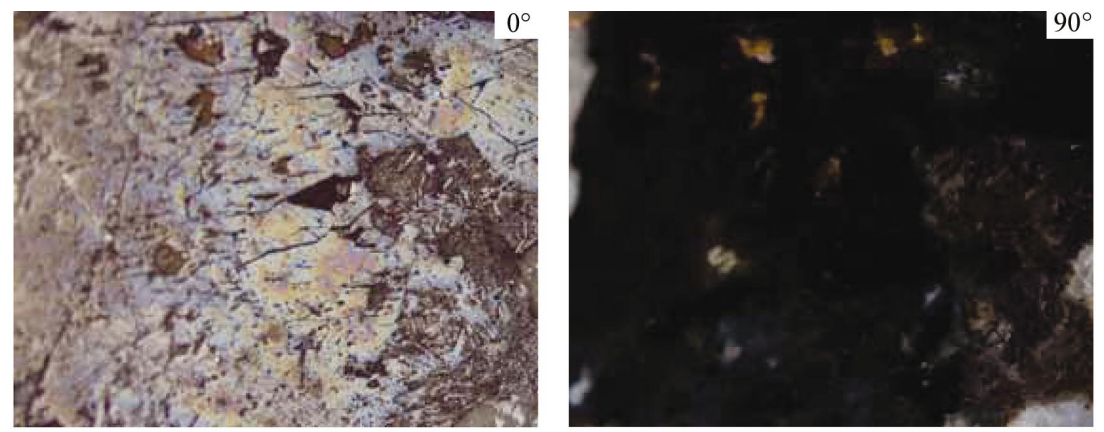

(b) Area $A$
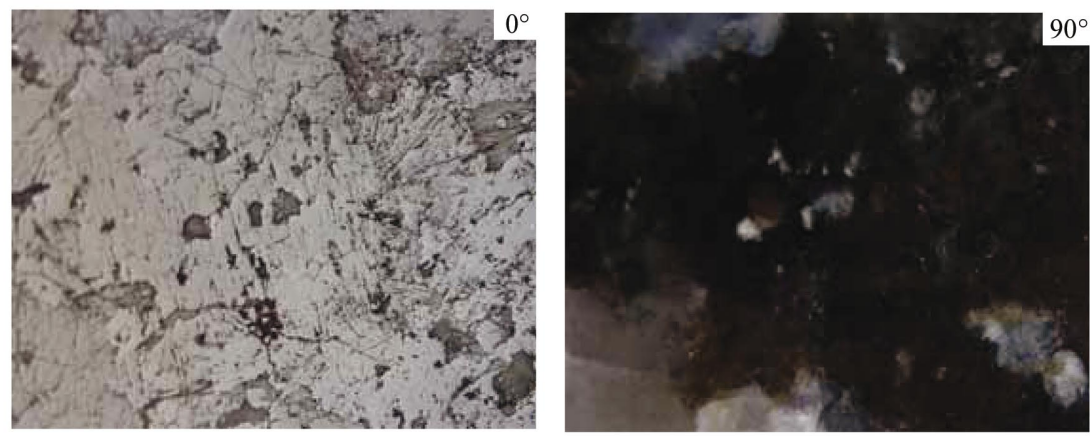

(c) Area $B$

\section{Figure 1}

(a) Optical microscope photograph of Tsukuba gabbroic rock. $(b)$ and $(c)$ show polarization microscope images under reflective conditions of the black area $A$ and the white area $B$, respectively. The angles of the polarizer are shown. These observed areas are selected from the sample area shown as solid frames in $(a)$, which correspond to analyzed areas for XAFS imaging. The dashed frames $(2.7 \mathrm{~mm} \times 3.4 \mathrm{~mm})$ indicate the viewing area for observation using the polarization microscope. 
performed for the whole colored parts. It has been found that the concentrations of sodium and potassium are smaller than $1 \%$ for both areas $A$ and $B$. From the data obtained using the electron-probe microanalyzer, one would notice that the yellowish-brown grains $A^{\prime}$ contain more iron but less aluminium compared with the surrounding black area $(A)$. Although yellowish-brown grains are found in area $B$, iron was not detected there. The major elements in white $B$ are calcium, silicon and aluminium; the black $A$ area principally includes magnesium, silicon, aluminium and iron. Combined with the X-ray diffraction patterns shown in Fig. 2, it was found that the minerals in areas $A$ and $B$ are mainly amphiboles (Puga et al., 1999) $\left[\mathrm{Al}_{3.2} \mathrm{Ca}_{3.4^{-}}\right.$ $\mathrm{Fe}_{4.0} \mathrm{~K}_{0.6} \mathrm{Mg}_{6.0} \mathrm{Na}_{1.0} \mathrm{Si}_{12.8} \mathrm{O}_{44}(\mathrm{OH})_{4} ; C 2 / m, a=9.89, b=18.03, c=$ $5.31 \AA, \quad \beta=105.20^{\circ}$ ] and feldspar (Hellmann et al., 2003) $\left(\mathrm{K}_{0.5} \mathrm{Na}_{0.5} \mathrm{AlSiO}_{8} ; P 1, a=8.529, b=12.945, c=7.189 \AA\right.$ А $, \alpha=90.36, \beta=$ $115.99, \gamma=88.8^{\circ}$ ), respectively. Some reflections, as indicated by the arrows in Fig. 2, are attributed neither to amphiboles nor feldspar. They are mainly identified as those from olivine, which is known as a solid solution of forsterite $\left(\mathrm{Mg}_{2} \mathrm{SiO}_{4}\right)$ and fayalite $\left(\mathrm{Fe}_{2} \mathrm{SiO}_{4}\right)$, but some weak reflections observed in the higher-angle range can be attributed to pyroxene or biotite. In addition, as shown in Fig. 3, synchrotron XRF spectra have revealed that even area $B$ contains

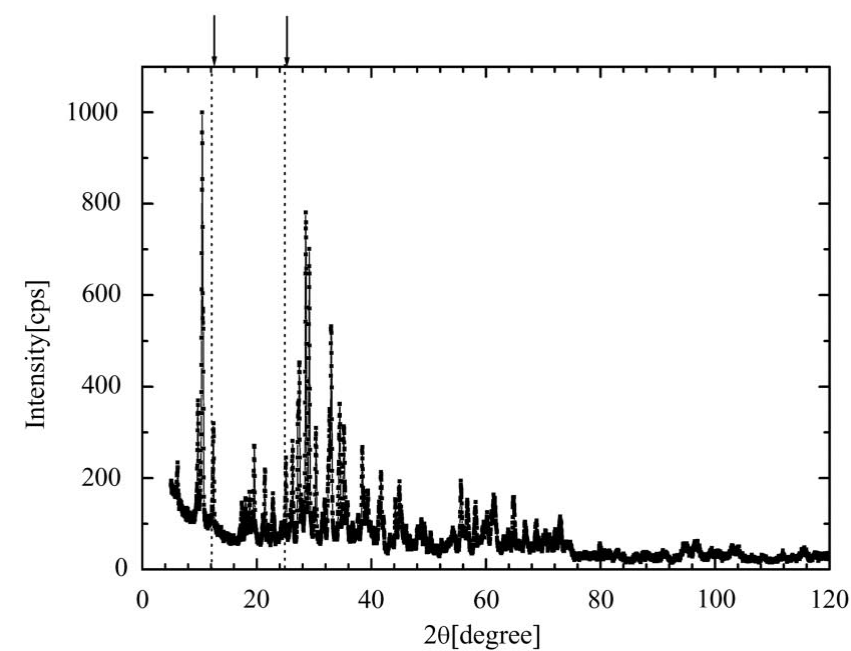

(a)

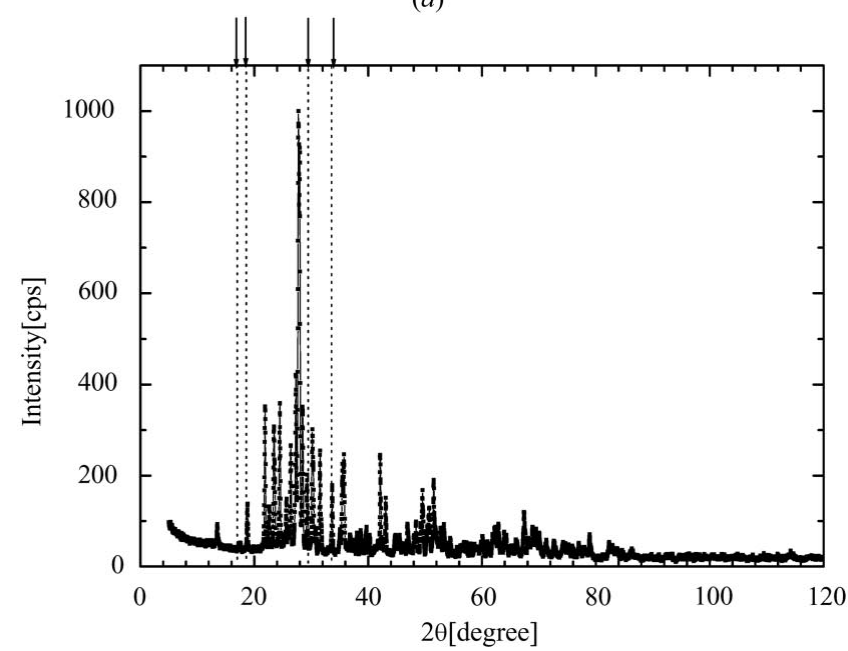

(b)

Figure 2

X-ray powder diffraction using $\mathrm{Cu} K \alpha$ radiation for areas (a) $A$ (black part) and $(b) B$ (white part). The arrows in the diffraction data show reflections that are from neither amphiboles nor feldspar. trace iron (almost 1.5-2 orders lower than that for area $A$ ) because of the significantly high sensitivity, although an electron-probe microanalyzer did not detect any trace elements. Although pure feldspar does not include iron, it has been generally reported that feldspar often contains colored grains. The origins of trace iron detected by synchrotron XRF spectra would be such included materials, presumably the yellowish-brown grains contained in the matrix of feldspar $(\operatorname{area} B)$.

Fig. 4 shows typical X-ray images of Tsukuba gabbroic rocks obtained using a non-scanning XRF microscope. The data were taken as a function of X-ray energy. Although the image is dark for $7025 \mathrm{eV}$, it becomes bright when the primary X-ray energy goes across the iron $K$-absorption edge $(7111 \mathrm{eV})$. This indicates that the sample contains iron in the whole area, but in particularly high concentrations in area $A$. One might note that some specific grains in the white part become bright at $7128 \mathrm{eV}$ and $7152 \mathrm{eV}$. These are diffraction spots, which satisfy the Bragg condition when the diffraction angle $2 \theta$ is around $91^{\circ}$. While scanning the energy around the iron $K$-absorption edge, at least seven different spots were observed; i.e. one from the black part, three from the white part and three from the boundary region.

Fig. 5 shows the Fe- $K$ XAFS spectra obtained by integrating the intensity in the XRF images for areas of $A$ and $B$, both of which are 150 pixels $\times 150$ pixels. No influence of diffraction lines from those parts was observed in the present case. Both spectra have very similar features in the near-edge region. Although there are no significant

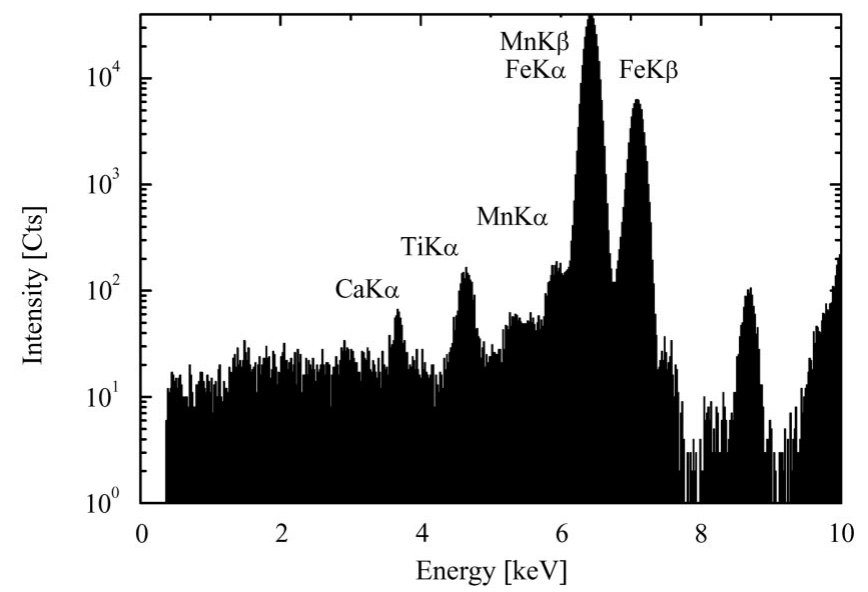

(a)

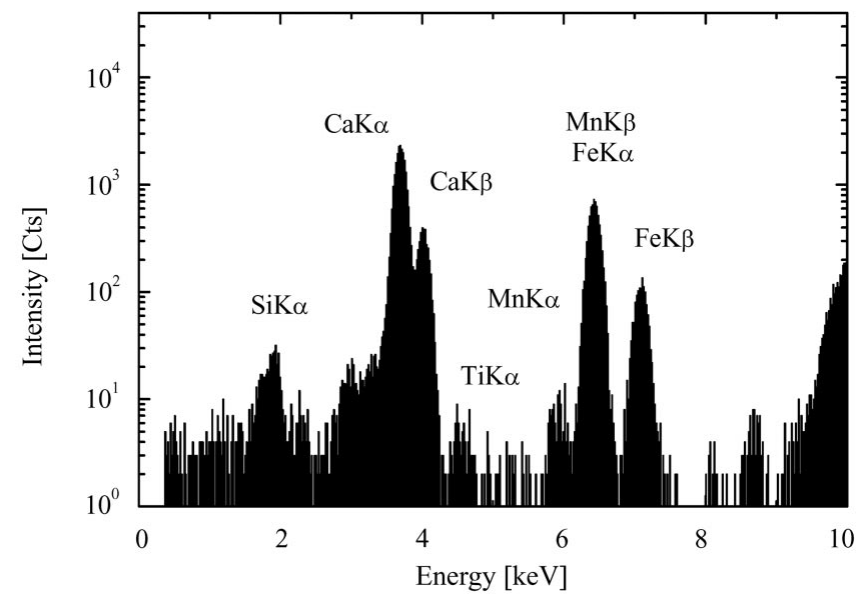

(b)

Figure 3

Synchrotron X-ray fluorescence spectra (incident X-ray energy $10 \mathrm{keV}$, measuring time $300 \mathrm{~s}$ ) for areas (a) $A$ (black part) and (b) $B$ (white part). 

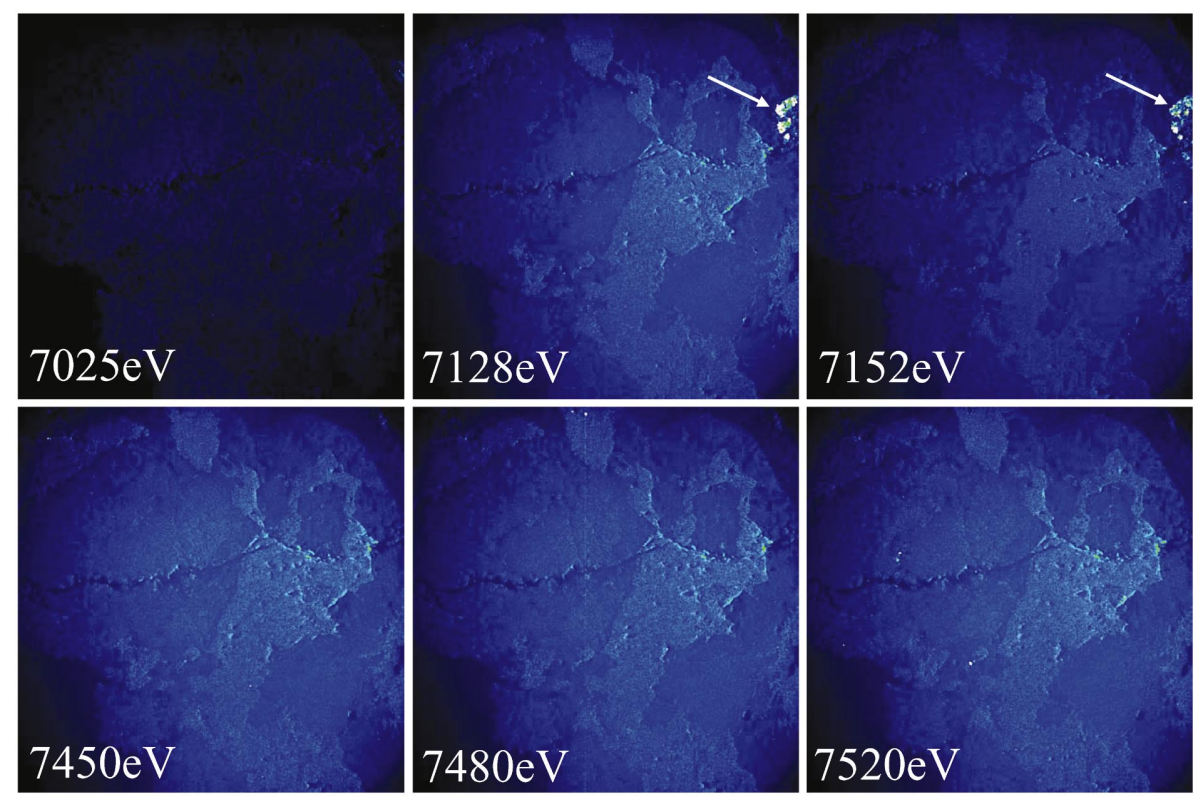

Figure 4

A series of XRF images obtained when the primary energy is scanned at around the Fe $K$-absorption edge. The view area is as shown in the optical microscope photograph in Fig. 1. Strong diffraction lines were observed at the right-hand side of the images for 7128 and $7152 \mathrm{eV}$. The spots indicated by arrows are due to grains with the same orientation.

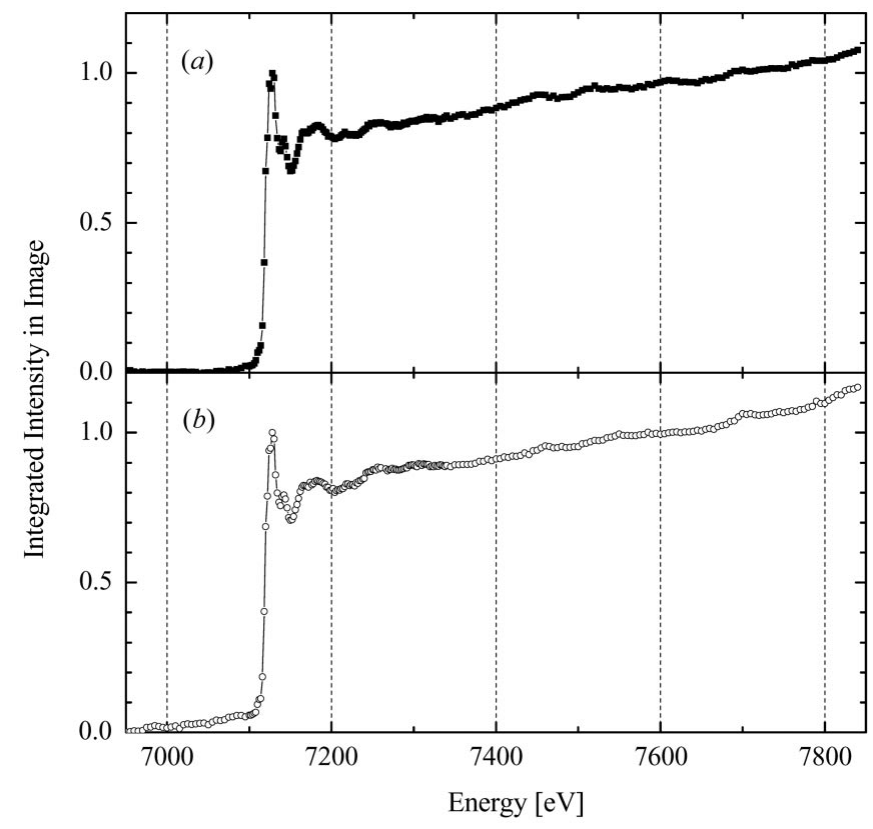

Figure 5

X-ray absorption spectra obtained from the integrated intensity of the XRF images for the selected areas corresponding to $(a)$ area $A$ (black part) and $(b)$ area $B$ (white part)

pre-edge structures in both spectra, a slight protuberance has sometimes been observed in the 7000-7100 eV region, which must be correlated with a certain crystal orientation (Dyar et al., 2002). In addition, the absorption-edge energy for both spectra is $7118 \mathrm{eV}$. The chemical shift is close to that of $\mathrm{FeO}$, although a spike peak $(\sim 7130 \mathrm{eV})$ was not normally observed for any simple oxides. The chemical state of the iron in both areas $A$ and $B$ seems quite similar.

The EXAFS functions, $k \chi(k)$, for these two parts are shown in Fig. 6. These profiles do not exhibit any particularly large differences, but one can see that the phase of the oscillations does not agree for higher $k$, around 9-12, suggesting the deviation of the atomic distances to the second-, third- and fourth-nearest neighboring atoms. Roughly speaking, both data are qualitatively similar to that of olivine, and the discrepancy between areas $A$ and $B$ can be explained as a difference in the mixed ratio of forsterite $\left(\mathrm{Mg}_{2} \mathrm{SiO}_{4}\right)$ and fayalite $\left(\mathrm{Fe}_{2} \mathrm{SiO}_{4}\right)$. This is most likely because the powder diffraction also indicates the existence of olivine as an impurity. However, it is also necessary to check other possibilities. One could notice that the present XAFS data obtained from the imaging experiments have some features such as quite a small amplitude around $k=5 \AA^{-1}$ and a broad structure at around $k=6 \AA^{-1}$, for both areas $A$ and $B$. The simulation based on the FEFF7 code (Zabinsky et al., 1995) indicates that the following four cases can reproduce these features: (i) the $\mathrm{Fe} 3$ site in biotite, (ii) the $\mathrm{Fe} 1$ and $\mathrm{Fe} 2$ sites in pyroxene, (iii) the $\mathrm{Fe} 2$ site in amphiboles, (iv) the $\mathrm{Fe} 1, \mathrm{Fe} 2$ and $\mathrm{Fe} 3$ sites in actinolite. However, it has been found that none of these cases can explain other parts of the XAFS oscillation. Therefore, coming back to olivine would be appropriate. The simulation considering different mixing ratios of forsterite and fayalite indicates that the local structure of iron in area $A$ can have quite a high iron concentration (low magnesium concentration), around $0.8-0.9$ or even more, while area $B$ can have $0.5-0.6$. In short, Fe- $K$ XAFS data for both areas $A$ and $B$ indicate olivine, which is observed as yellowish-brown particles using an optical microscope. The main differences in Fig. 6 would be due to a different concentration ratio of iron and magnesium, concerning the solution limit of magnesium for the surrounding minerals, amphiboles and feldspar for $A$ and $B$, respectively. While amphiboles can contain quite large amounts of magnesium, feldspar excludes it. Such differences in the solution limit of magnesium could influence the chemical composition of yellowish-brown grains contained in areas $A$ and $B$.

Fig. 7(a) shows the magnitude of the Fourier transform for $k \chi(k)$ in Fig. 6. The calculated results for amphibole, olivine and fayalite are also shown in Fig. 7(b) as references. The model used for olivine has been prepared simply by putting magnesium at $50 \%$ of the iron sites in fayalite. The result clearly indicates that experimentally obtained data for both $A$ and $B$ are quite close to olivine and fayalite rather than to amphibole. The first $(1.87 \AA)$ and second $(2.91 \AA)$ peaks for area $A$ correspond to $\mathrm{Fe}-\mathrm{O}$ and $\mathrm{Fe}-\mathrm{Si}$ pairs, respectively. The third peak (3.52 $\AA$ ) is due to $\mathrm{Fe}-\mathrm{Fe}$ (also including some $\mathrm{Fe}-\mathrm{Mg}$ ), $\mathrm{Fe}-\mathrm{Si}$ and another $\mathrm{Fe}-\mathrm{Fe}(\mathrm{Mg})$ pairs. The simulation indicates that both the second and third peaks depend on the iron concentration, i.e. they become quite strong when the amount of iron increases. On the other hand, the first peak is not so sensitive, but the profile is fairly influenced. As mentioned earlier, the matrix of area $A$ is amphibole, and the iron in the matrix also contributes. The mineral has a basic structure of $\mathrm{SiO}_{4}$ chains and $\mathrm{Fe}$ at the octahedrals, where the $\mathrm{Fe}-\mathrm{O}$ and Fe-Si pairs are 2.07-2.14 $\AA$ and $2.70 \AA$, respectively. In the same way, for area $B$ the first $(1.89 \AA)$, second $(2.48 \AA)$ and third $(3.53 \AA)$ peaks are interpreted as $\mathrm{Fe}-\mathrm{O}, \mathrm{Fe}-\mathrm{Si}$ and $\mathrm{Fe}-\mathrm{Fe}(\mathrm{Mg})$ pairs, respectively. The positions for each peak are close to those for area $A$, indicating that the basic atomic arrangement is quite similar. It is 


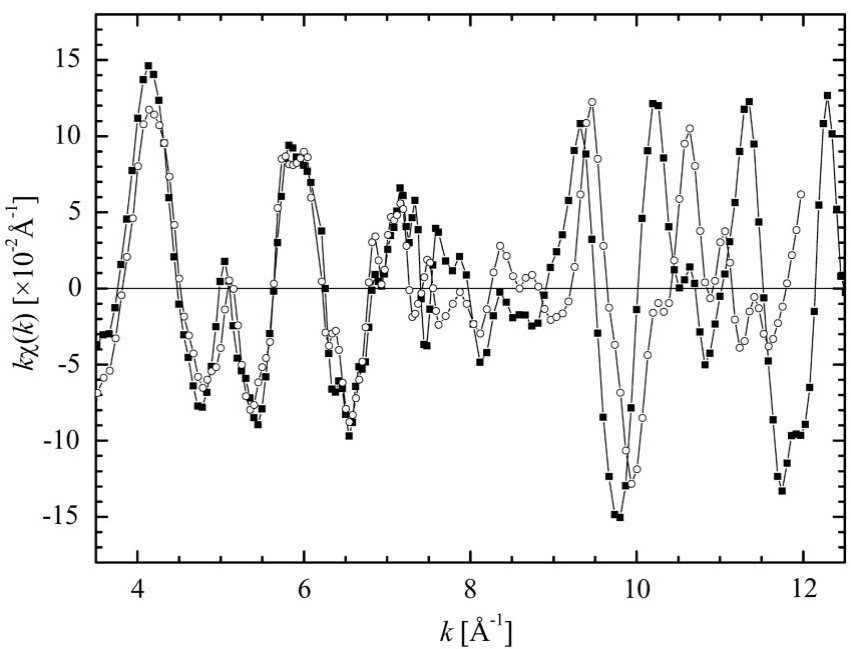

Figure 6

X-ray absorption fine-structure function $k \chi(k)$ extracted from Fig. 5 ( $k$ is a photoelectron wavevector). Solid squares and open circles are data from area $A$ (black part) and area $B$ (white part), respectively.

noticeable that $\mathrm{Fe}-\mathrm{Si}$ and $\mathrm{Fe}-\mathrm{Fe}(\mathrm{Mg})$ are quite weak. This is mainly due to some disorder caused by the existence of magnesium randomly substituted to the iron site in the crystal. The inhomogeneous solubility of fayalite in olivine could further complicate the problem.

\section{Conclusion}

The chemical composition and structure of Tsukuba gabbroic rocks have been studied. The sample has two typical mineral textures, black amphibole (area $A$ ) and white feldspar (area $B$ ). In the present research the atomic structure around iron in both areas was investigated by Fe $K$-edge XAFS imaging using a non-scanning XRF microscope, which is quite a new procedure for extremely rapid imaging. Although the concentration in both areas is fairly different, it was found that the respective local structure is quite similar between areas $A$ and $B$. The most likely reason is that small yellowish-brown particles mainly contributed to Fe $K$-edge XAFS and that they have quite similar atomic structures. The main difference is the phase of the oscillations for higher $k$, indicating the deviation of the middle-range atomic distances. The XAFS analysis reveals that iron in both black amphibole (area $A$ ) and white feldspar (area $B$ ) is considered to be mainly from olivine, which is a solid solution of forsterite and fayalite, although the ratio is fairly different between them. During the present research the feasibility of the present XAFS imaging technique has been demonstrated. The most significant advantage would be the capability of simultaneous data collection for a large number of pixels as a function of X-ray energy. This novel tool will be widely used for realistic inhomogeneous samples in many sciences.

The authors would like to thank Dr Hiromi Eba for the contribution in the early stage of the present research. Their thanks also go to Professors Hiroshi Sawa, Yuhsuke Wakabayashi and Yoshinori Uchida (Photon Factory) for their kind assistance during the experiments. This work was performed with the approval of the Photon Factory Program Advisory Committee (Proposal No. 2002S2003), and was partly supported by the Active Nano-Characterization and Technology Project, Special Coordination Funds of the MEXT, Japanese Government.

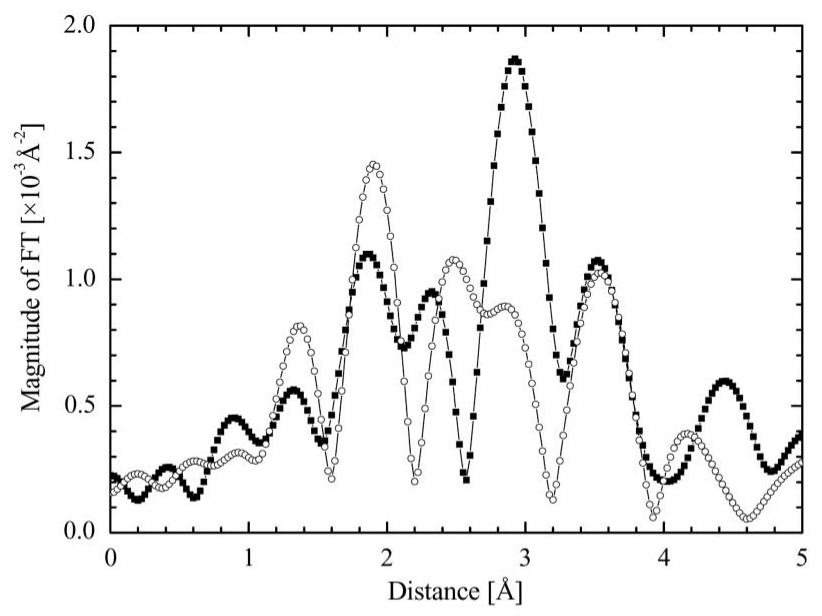

(a)

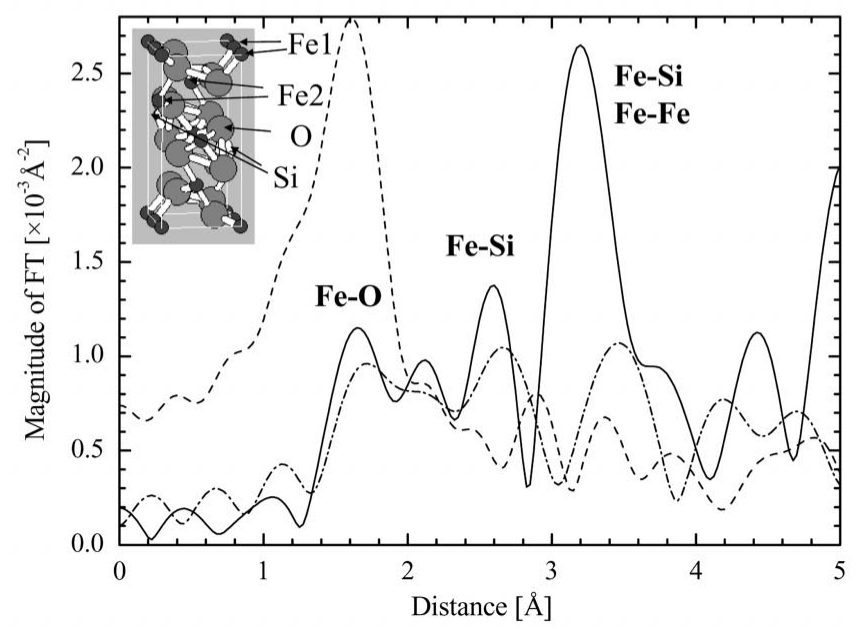

(b)

Figure 7

(a) Magnitude of the Fourier transform of $k \chi(k)$ shown in Fig. 6. Solid squares and open circles are data from areas $A$ (black part) and $B$ (white part), respectively. The $k$ range used for the Fourier transform is $4.98-12.14 \AA^{-1}$ and 3.81-11.8 $\AA^{-1}$, respectively. (b) Magnitude of the Fourier transform of $k \chi(k)$ given by a $F E F F$ simulation for amphibole (dashed line), olivine (dot-dashed line) and fayalite (solid line). As for the chemical composition of olivine, a 1:1 solid solution of forsterite and fayalite is assumed in the present case. The model is considered by simply replacing $50 \%$ of iron with magnesium in fayalite. The $k$ range used for the Fourier transform is $3.54-11.79 \AA^{-1}, 4.50$ $11.70 \AA^{-1}$ and $4.73-12.16 \AA^{-1}$ for amphibole, olivine and fayalite, respectively. The scale for amphibole was reduced by $50 \%$. The inset shows the crystal structure of fayalite, which is expected to be close to the mineral in $A$ because of quite a high concentration of iron.

\section{References}

Dyar, M. D., Gunter, M. E., Delaney, J. S., Lanzarotti, A. \& Sutton, S. R. (2002). Can. Mineral. 40, 1375-1393.

Hellmann, R., Penisson, J. M., Hernig, R. L., Thomassin, J. H. \& Abrioux, M. F. (2003). Phys. Chem. Miner. 30, 192-197.

Miyazaki, K., Sasada, M. \& Yoshioka, T. (1996). Geology of the Makabe District. Geological Survey of Japan. (In Japanese.)

Puga, E., Cruz, M. D. R. \& De Federico, A. D. (1999). Can. Mineral. 37, $1191-$ 1209.

Sakurai, K. (1999). Spectrochim. Acta, B54, 1497-1503.

Sakurai, K. \& Eba, H. (2003). Anal. Chem. 75, 355-359.

Sakurai, K. \& Mizusawa, M. (2004). Proceedings of the 8th International Conference on Synchrotron Radiation Instrumentation. In the press.

Welch, M. D. \& Knight, K. S. (1999). Eur. J. Mineral. 11, 321-331.

Yang, H. \& Hirschmann, M. M. (1995). Am. Mineral. 80, 916-922.

Zabinsky, S. I., Rehr, J. J., Ankudinov, A., Albers, R. C. \& Eller, M. J. (1995). Phys. Rev. B, 52, 2995-3009. 